\title{
Taste Masking of Ondansetron Hydrochloride by Polymer Carrier System and Formulation of Rapid-Disintegrating Tablets
}

Submitted: July 23, 2006; Accepted: January 17, 2007; Published: June 22, 2007

Shagufta Khan, ${ }^{1}$ Prashant Kataria, ${ }^{1}$ Premchand Nakhat, ${ }^{1}$ and Pramod Yeole ${ }^{1}$

${ }^{1}$ Institute of Pharmaceutical Education and Research (IPER), Borgaon (Meghe), Wardha 442001, Maharashtra, India.

\section{AbSTRACT}

The purpose of this research was to mask the intensely bitter taste of ondansetron $\mathrm{HCl}$ and to formulate a rapiddisintegrating tablet (RDT) of the taste-masked drug. Taste masking was done by complexing ondansetron $\mathrm{HCl}$ with aminoalkyl methacrylate copolymer (Eudragit EPO) in different ratios by the precipitation method. Drug-polymer complexes (DPCs) were tested for drug content, in vitro taste in simulated salivary fluid (SSF) of $\mathrm{pH}$ 6.2, and molecular property. Complex that did not release drug in SSF was considered taste-masked and selected for formulation RDTs. The complex with drug-polymer ratio of 8:2 did not show drug release in SSF; therefore, it was selected. The properties of tablets such as tensile strength, wetting time, water absorption ratio, in vitro disintegration time, and disintegration in the oral cavity were investigated to elucidate the wetting and disintegration characteristics of tablets. Polyplasdone XL-10 7\% wt/wt gave the minimum disintegration time. Tablets of batch F4 containing spray-dried mannitol and microcrystalline cellulose in the ratio 1:1 and $7 \% \mathrm{wt} / \mathrm{wt}$ Polyplasdone XL-10 showed faster disintegration, within 12.5 seconds, than the marketed tablet (112 seconds). Good correlation between in vitro disintegration behavior and in the oral cavity was recognized. Taste evaluation of RDT in human volunteers revealed considerable taste masking with the degree of bitterness below threshold value (0.5) ultimately reaching to 0 within 15 minutes, whereas ondansetron $\mathrm{HCl}$ was rated intensely bitter with a score of 3 for 10 minutes. Tablets of batch $\mathrm{F} 4$ also revealed rapid drug release ( $\mathrm{t}_{90}, 60$ seconds) in SGF compared with marketed formulation ( $\mathrm{t}_{90}, 240$ seconds; $\left.P<.01\right)$. Thus, results conclusively demonstrated successful masking of taste and rapid disintegration of the formulated tablets in the oral cavity.

KEYWORDS: Taste masking, rapid-disintegrating tablets, ondansetron $\mathrm{HCl}$, Eudragit EPO, superdisintegrants.

Corresponding Author: Shagufta Khan, Department of

Pharmaceutics, Institute of Pharmaceutical Education and Research (IPER), Borgaon (Meghe), Wardha 442001, Maharashtra, India. Tel: +91 07152 240284; Fax: +91 07152 241684; E-mail: shaguftakhan17@rediffmail.com

\section{INTRODUCTION}

In recent decades, a variety of pharmaceutical research has been conducted to develop new dosage forms. Considering quality of life, most of these efforts have been focused on ease of medication. ${ }^{1}$ Among the dosage forms developed to facilitate ease of medication, the rapid disintegrating tablet (RDT) is one of the most widely employed commercial products. ${ }^{2-4}$ The RDT has remarkable disintegration properties; it can rapidly disintegrate without water in the mouth within a few seconds. When an RDT is placed in the oral cavity, saliva quickly penetrates into the pores causing rapid disintegration.

RDTs are useful in patients, ${ }^{4,5}$ such as pediatric, geriatric, bedridden, or developmentally disabled, who may face difficulty in swallowing conventional tablets or capsules and liquid orals or syrup, ${ }^{6}$ leading to ineffective therapy, ${ }^{7}$ with persistent nausea, sudden episodes of allergic attacks, or coughing for those who have an active life style. ${ }^{8}$ RDTs are also applicable when local action in the mouth is desirable such as local anesthetic for toothaches, oral ulcers, cold sores, or teething, ${ }^{9}$ and to deliver sustained release multiparticulate system to those who cannot swallow intact sustained action tablets/capsules. ${ }^{10}$

Ondansetron $\mathrm{HCl}$ is a potent antiemetic drug ${ }^{11}$ indicated for the treatment and/or prophylaxis of postoperative or chemotherapy- or radiotherapy-induced emesis and also used in the early onset of alcoholism. ${ }^{12}$ In general, emesis is preceded with nausea and in such condition it is difficult to administer drug with a glass of water; hence it is beneficial to administer such drugs as RDTs. Ondansetron $\mathrm{HCl}$ is an intensely bitter drug; hence, if it is incorporated directly into an RDT the main objective behind formulation of such a dosage form will definitely get futile. ${ }^{2,13,14}$ Thus in the present study an attempt has been made to mask the taste of ondansetron $\mathrm{HCl}$ and to formulate RDTs with good mouth feel so as to prepare a "patient-friendly dosage form."

\section{MATERIALS AND METHODS}

\section{Materials}

Ondansetron $\mathrm{HCl}$ (Batch No. B12005) was a gift from Neon Laboratories (Palgher, India). Aminoalkyl methacrylate copolymer (Eudragit EPO) was a gift from Degussa India Private Ltd (Mumbai, India). The diluents used were 
AAPS PharmSciTech 2007; 8 (2) Article 46 (http://www.aapspharmscitech.org).

Table 1. Drug Content and In Vitro Taste Evaluation of DPCS in SSF

\begin{tabular}{lccc}
\hline Serial No. & $\begin{array}{c}\text { Drug-Polymer Ratio } \\
\text { in DPC }\end{array}$ & $\begin{array}{c}\text { Amount of Ondansetron } \mathrm{HCl} \\
\text { per 100 mg of DPC }\end{array}$ & \% Drug Dissolved in SSF* \\
\hline 1 & $7.0: 3.0$ & $69.52 \pm 0.05$ & ND \\
2 & $7.5: 2.5$ & $73.50 \pm 0.32$ & ND \\
3 & $8.0: 2.0$ & $78.43 \pm 0.56$ & $0.80 \pm 0.32$ \\
4 & $8.5: 1.5$ & $83.92 \pm 0.51$ & $2.00 \pm 0.21$ \\
5 & $9.0: 1.0$ & $89.19 \pm 0.65$ & $4.60 \pm 0.42$ \\
6 & $9.5: 0.5$ & $94.21 \pm 0.48$ & \\
\hline
\end{tabular}

*Results are the mean of 3 observations \pm SD.

ND indicates not detectable

microcrystalline cellulose (Ceolus KG 802, Asahi Kasei Chemicals Corporation, Tokyo, Japan), spray-dried mannitol (Parteck M 200, Merck, Darmstadt, Germany), and spraydried lactose (Flowlac 100, Meggle, Wasseburg, Germany). The superdisintegrants were crospovidone (Polyplasdone XL-10, ISP Technologies, Inc, Calvert City, KY), croscarmellose sodium (Ac-Di-Sol, FMC Biopolymer, Wallingstown, Ireland) and sodium starch glycolate (Primojel, DMV International, Belle Mead, NJ). All other chemicals used in the study were of analytical grade.

\section{Preparation of Drug-Polymer Complex (DPC)}

Ondansetron $\mathrm{HCl}$ and Eudragit EPO complex were prepared using the precipitation method. Saturated solutions of ondansetron $\mathrm{HCl}$ and Eudragit EPO were prepared in absolute ethanol in various ratios (Table 1) and injected into $0.1 \mathrm{~N}$ sodium hydroxide with constant stirring at $500 \mathrm{rpm}$ in a mechanical stirrer. The foamy matrix obtained on the top of the solution was separated and dried at room temperature for 24 hours under vacuum. The dried matrix was subsequently pulverized and finally stored in a tightly closed container for further studies.

\section{Characterization of DPC Drug Content, In Vitro Taste Evaluation, and Molecular Properties}

Drug content was determined by dissolving $100 \mathrm{mg}$ of DPC in $500 \mathrm{~mL}$ of simulated gastric fluid (SGF) and analyzing $1 \mathrm{~mL}$ of appropriately diluted sample at $249 \mathrm{~nm}$ (Table 1).

In vitro taste was evaluated by determining drug release in simulated salivary fluid (SSF) (pH 6.2) to predict release in the human saliva. DPC, equivalent to $10 \mathrm{mg}$ of ondansetron $\mathrm{HCl}$ (equivalent to $8 \mathrm{mg}$ ondansetron, ie, its dose), was placed in $10 \mathrm{~mL}$ of SSF and shaken for 60 seconds. The amount of drug released was analyzed at $249 \mathrm{~nm}$ (Table 1).

Molecular properties on complexation were studied by $\mathrm{x}$ ray powder diffraction (XRPD) and Fourier transform infrared spectroscopy (FTIR). The X-ray powder diffractograms of the DPC (8:2), ondansetron $\mathrm{HCl}$, Eudragit EPO, and physical mixture of ondansetron $\mathrm{HCl}$ and Eudragit EPO (8:2) were recorded using a Philips PW 1729 X-ray diffractometer (Legroupe Interconnection, Saint Jurie, Clubac, Canada) with monocrotized $\mathrm{Cu} \mathrm{K} \alpha$ radiation $\left(1.314 \mathrm{~A}^{0}\right)$, at a speed of $2 \theta \mathrm{min}^{-1}$ from $10^{\circ}$ to $60^{\circ}(2 \theta)$ under the voltage and current of $40 \mathrm{Kv}$ and $30 \mathrm{Kv}$ respectively (Figure 1). Infrared (IR) spectra of these samples were obtained by $\mathrm{KBr}$ disc method (8400 S, Shimadzu Asia Pacific Pvt. Ltd, Singapore) in the range of 4000 to $500 \mathrm{~cm}^{-1}$ (Figure 2).

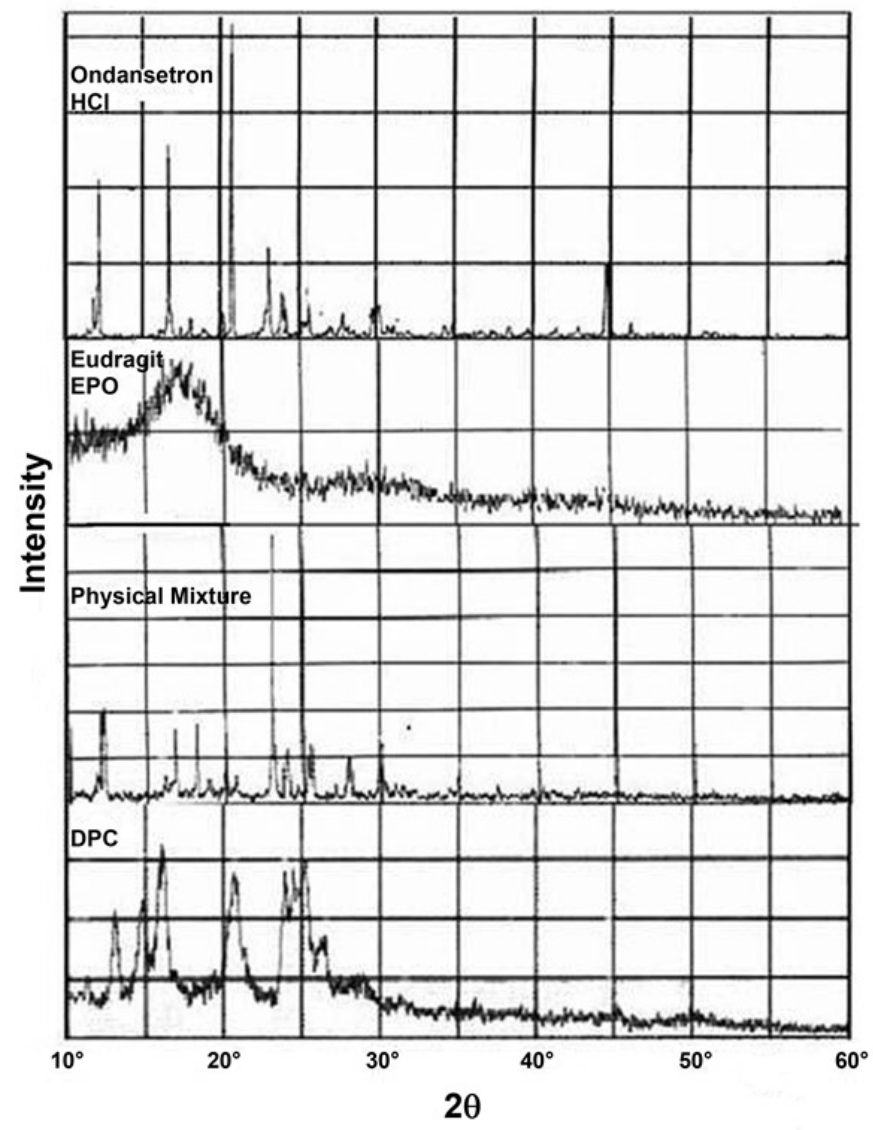

Figure 1. X-ray powder diffractograms of ondansetron $\mathrm{HCl}$, Eudragit EPO, physical mixture of ondansetron $\mathrm{HCl}$ and Eudragit EPO, and drug-polymer complexes (DPC). 
AAPS PharmSciTech 2007; 8 (2) Article 46 (http://www.aapspharmscitech.org).

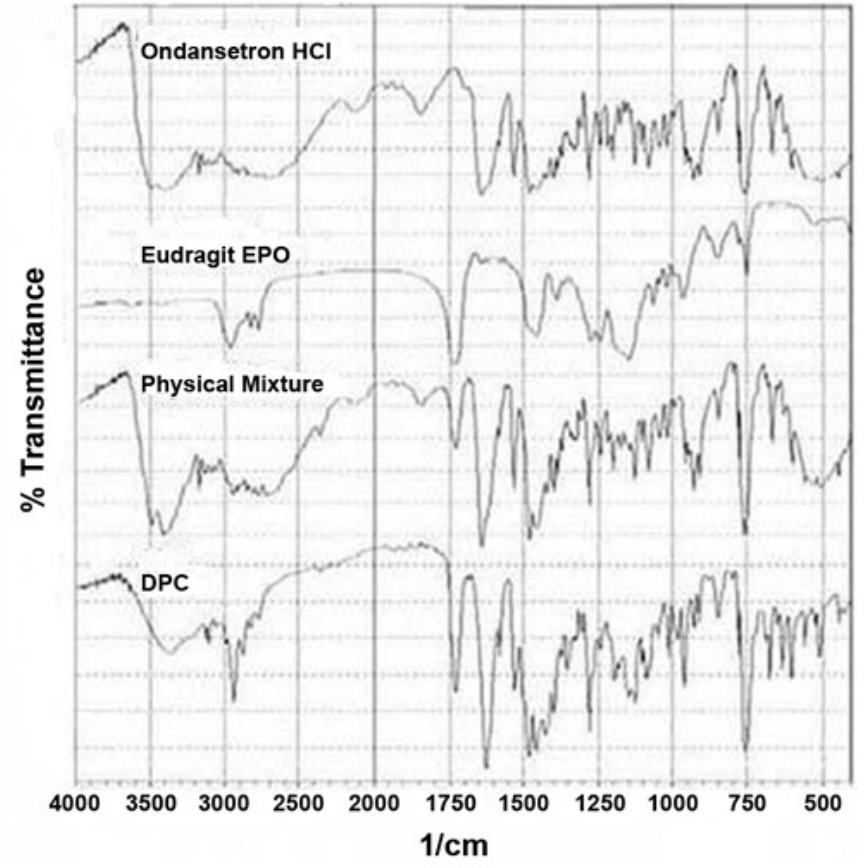

Figure 2. Fourier transform infrared spectra of ondansetron $\mathrm{HCl}$, Eudragit EPO, physical mixture of ondansetron $\mathrm{HCl}$ and Eudragit EPO, and drug-polymer complexes (DPC).

\section{Selection of Superdisintegrant and Formulation of RDTs}

Before formulation of tablets, the best superdisintegrant among Polyplasdone XL-10, Ac-Di-Sol, and Primojel was screened out. Tablets were prepared in various batches containing a blend of microcrystalline cellulose and spray-dried mannitol (1:1) as a diluent and superdisintegrant in various concentrations (Table 2). The best superdisintegrant screened was used for the final formulation of tablets (Table 3). Tablets were prepared by direct compression using $8-\mathrm{mm}$ flatfaced punches.

\section{Physical Properties of the Tablet Blend ${ }^{15}$}

Physical properties such as bulk density, tapped density, compressibility index, and the angle of repose of blend were determined (Table 4). Bulk density was determined by the USP method I; tapped density was determined by USP method II using a tapped density tester (Electrolab, ETD 1020, Mumbai, India). Percent compressibility and Hausner ratio were calculated using Equations 1 and 2:

$$
\begin{gathered}
\text { Percent compressibility }=\{(D t-D b) / D t\} \times 100 \\
\text { Hausner ratio }=\frac{D t}{D b}
\end{gathered}
$$

where, $\mathrm{Dt}$ and $\mathrm{Db}$ are tapped and bulk densities.

\section{Evaluation of Tablets}

Wetting Time and Water Absorption Ratio ${ }^{16}$

A piece of tissue paper folded twice was kept in a culture dish (internal diameter $5.5 \mathrm{~cm}$ ) containing $\sim 6 \mathrm{~mL}$ of purified water. A tablet having a small amount of amaranth powder on the upper surface was placed on the tissue paper. The time required to develop a red color on the upper surface of the tablet was recorded as the wetting time. The same procedure without amaranth was followed for determining the water absorption ratio. The wetted tablet was weighed and the water absorption ratio, $\mathrm{R}$, was determined according to the following equation,

$$
R=\left\{\frac{\left(W_{a}-W_{b}\right)}{W_{b}}\right\} \times 100
$$

where, $\mathrm{W}_{\mathrm{b}}$ and $\mathrm{W}_{\mathrm{a}}$ were the weights of the tablet before and after study.

Tablets were also evaluated for hardness, tensile strength, friability, weight variation, and drug content (Table 5).

\section{In Vitro Disintegration Study}

In vitro disintegration time for RDTs was determined using USP and modified disintegration apparatus with SSF ( $\mathrm{pH}$ 6.2) as the disintegrating medium. During this study we made an attempt to develop a more suitable apparatus for RDT (Figure 3) because many reports ${ }^{17-20}$ indicated the unsuitability of the conventional disintegration test apparatus for RDT. Briefly, the apparatus consisted of a glass beaker

Table 2. Disintegration Time of Different Superdisintegrants

\begin{tabular}{lcccc}
\hline Batch & Disintegrant & $\begin{array}{c}\text { Disintegrant, } \\
\% \mathrm{wt} / \mathrm{wt}\end{array}$ & $\begin{array}{c}\text { Diluent, } \\
\% \mathrm{wt} / \mathrm{wt} \mathrm{t}^{*}\end{array}$ & $\begin{array}{c}\text { Disintegration } \\
\text { Time, } \mathrm{s}^{\dagger}\end{array}$ \\
\hline $\mathrm{A} 1$ & - & - & 100 & 65 \\
$\mathrm{~A} 2$ & $\mathrm{CRP}$ & 5 & 95 & 11 \\
$\mathrm{~A} 3$ & $\mathrm{CRP}$ & 6 & 94 & 8 \\
$\mathrm{~A} 4$ & $\mathrm{CRP}$ & 7 & 93 & 7 \\
$\mathrm{~A} 5$ & $\mathrm{CRP}$ & 8 & 92 & 8 \\
$\mathrm{~A} 6$ & $\mathrm{CRP}$ & 10 & 90 & 10 \\
$\mathrm{~A} 7$ & $\mathrm{CRP}$ & 12 & 88 & 10 \\
$\mathrm{~A} 8$ & $\mathrm{CCS}$ & 8 & 92 & 31 \\
A9 & $\mathrm{CCS}$ & 10 & 90 & 24 \\
A10 & CCS & 12 & 88 & 18 \\
A11 & SSG & 8 & 92 & 42 \\
A12 & SSG & 10 & 90 & 39 \\
A13 & SSG & 12 & 88 & 32 \\
\hline CRP indicates Polyplasdone XL-10 (Crospovidone); CCS, Ac-Di-Sol \\
(Croscarmellose sodium); SSG, Primojel (Sodium starch glycolate); \\
-, ingredient not added. \\
*1:1 mixture of microcrystalline cellulose and spray-dried mannitol. \\
†n $=$ 3.
\end{tabular}


AAPS PharmSciTech 2007; 8 (2) Article 46 (http://www.aapspharmscitech.org).

Table 3. Composition of Rapid-Disintegrating Tablets

\begin{tabular}{|c|c|c|c|c|c|c|c|}
\hline \multirow[b]{2}{*}{ Ingredients, $\mathrm{mg}$} & \multicolumn{7}{|c|}{ Batch } \\
\hline & F1 & $\mathrm{F} 2$ & F3 & F4 & F5 & F6 & F7 \\
\hline $\mathrm{DPC}$ & 12.76 & 12.76 & 12.76 & 12.76 & 12.76 & 12.76 & 12.76 \\
\hline Microcrystalline cellulose & 99.74 & - & - & 49.87 & 49.87 & 33.25 & 33.25 \\
\hline Spray-dried mannitol & - & 99.74 & - & 49.87 & - & 66.50 & - \\
\hline Spray-dried lactose & - & - & 99.74 & - & 49.87 & - & 66.50 \\
\hline Polyplasdone XL-10 & 8.75 & 8.75 & 8.75 & 8.75 & 8.75 & 8.75 & 8.75 \\
\hline Aspartame & 2.50 & 2.50 & 2.50 & 2.50 & 2.50 & 2.50 & 2.50 \\
\hline Magnesium stearate & 1.25 & 1.25 & 1.25 & 1.25 & 1.25 & 1.25 & 1.25 \\
\hline Mint flavor & QS & QS & QS & QS & QS & QS & QS \\
\hline Orange flavor & QS & QS & QS & QS & QS & QS & QS \\
\hline
\end{tabular}

DPC indicates drug polymer complex. Formula for one tablet is shown in the table. Each tablet contains $10 \mathrm{mg}$ of ondensatron $\mathrm{HCl}$; QS, quantity sufficient.

of 1000-mL capacity with the wire basket positioned in the beaker with the help of a support in a way that when the beaker contained $900 \mathrm{~mL}$ of disintegrating medium, the basket had only $6 \mathrm{~mL}$ of it. A magnetic bead was placed at the bottom of the beaker maintained at $37 \pm 2^{\circ} \mathrm{C}$. Disintegration time was determined at 25 and $50 \mathrm{rpm}$ and compared with results obtained from the USP disintegration test apparatus and the in vivo disintegration test.

\section{In Vivo Disintegration Time, Sensory Evaluation of Roughness $^{20}$ and Taste Evaluation ${ }^{21,22}$}

In vivo disintegration was performed on 6 healthy human volunteers, from whom informed consent was first obtained. One tablet was held in the mouth after rinsing and the time required for complete disintegration of the tablet was recorded (Table 6). The disintegrated material was held in the mouth for another 60 seconds, and then spat out. The mouth was rinsed with water without swallowing the disintegrated material and, finally, the roughness levels were recorded on a numerical scale ranging from 0 to 3 where $0,1,2$, and 3 indicate no, slight, moderate, and high roughness, respectively. Taste evaluation was done using the time intensity method on 11 healthy human volunteers from whom informed consent was first obtained. The DPC equivalent of $10 \mathrm{mg}$ of ondansetron $\mathrm{HCl}$ was held in the mouth for 10 seconds and then spat out, and 1 RDT (containing $10 \mathrm{mg}$ ondansetron $\mathrm{HCl}$ ) was held in the mouth until complete disintegration. Bitterness was recorded immediately and at several intervals for 15 minutes according to the bitterness intensity scale from 0 to 3 where $0,0.5,1,2$, and 3 indicate no, threshold, slight, moderate, and strong bitterness (Table 7).

\section{Dissolution Study of Tablets}

In vitro dissolution study on prepared tablets (batch F4) and marketed tablet was done in $500 \mathrm{~mL}$ SGF without enzymes using USP type II (paddle) apparatus at $50 \mathrm{rpm}$ and $37 \pm$ $0.5^{\circ} \mathrm{C}$ (Figure 4).

\section{RESULTS AND DISCUSSION}

\section{Characterization of DPCs}

Percentage drug loading in DPCs was found from 98.0 to 99.31. No drug release was observed in SSF from complexes with the drug-polymer ratio of $8: 2$ and ratios with lesser drug, therefore, the ratio 8:2 was considered the optimal DPC with complete masking of bitter taste for further studies.

The x-ray diffractogram of ondansetron $\mathrm{HCl}$ confirms its crystalline nature, as evidenced from the number of sharp and intense peaks (Figure 1). The diffractogram of polymer (Eudragit EPO) showed diffused peaks, indicating its amorphous nature while the diffraction pattern of the drug polymer physical mixture showed simply the sum of the characteristic peaks of pure drug and the diffused peaks of

Table 4. Physical Properties of Tablet Blend*

\begin{tabular}{|c|c|c|c|c|c|c|c|}
\hline \multirow[b]{2}{*}{ Property } & \multicolumn{7}{|c|}{ Formulation } \\
\hline & $\mathrm{F} 1$ & $\mathrm{~F} 2$ & F3 & $\mathrm{F} 4$ & F5 & F6 & F7 \\
\hline Angle of repose, degrees & $42.16 \pm 0.55$ & $21.56 \pm 0.65$ & $22.11 \pm 0.51$ & $28.01 \pm 0.44$ & $28.88 \pm 0.32$ & $24.02 \pm 0.47$ & $24.76 \pm 0.32$ \\
\hline Bulk density, $\mathrm{g} / \mathrm{cm}^{3}$ & $0.26 \pm 0.29$ & $0.46 \pm 0.63$ & $0.49 \pm 0.25$ & $0.49 \pm 0.36$ & $0.51 \pm 0.24$ & $0.47 \pm 0.19$ & $0.51 \pm 0.20$ \\
\hline Tapped density $\mathrm{g} / \mathrm{cm}^{3}$ & $0.35 \pm 0.35$ & $0.50 \pm 0.42$ & $0.54 \pm 0.28$ & $0.58 \pm 0.19$ & $0.60 \pm 0.39$ & $0.54 \pm 0.23$ & $0.57 \pm 0.15$ \\
\hline$\%$ Compressibility & $25.48 \pm 0.13$ & $8.37 \pm 0.17$ & $9.82 \pm 0.23$ & $14.43 \pm 0.30$ & $15.04 \pm 0.37$ & $11.47 \pm 0.18$ & $11.73 \pm 0.09$ \\
\hline Hausner ratio & $1.34 \pm 0.16$ & $1.10 \pm 0.17$ & $1.16 \pm 0.14$ & $1.17 \pm 0.14$ & $1.17 \pm 0.12$ & $1.12 \pm 0.16$ & $1.13 \pm 0.10$ \\
\hline
\end{tabular}

*Values shown in table are the mean of 3 determinations \pm SD. 
AAPS PharmSciTech 2007; 8 (2) Article 46 (http://www.aapspharmscitech.org).

Table 5. Evaluation of Tablets*

\begin{tabular}{|c|c|c|c|c|c|c|c|}
\hline \multirow[b]{2}{*}{ Parameters } & \multicolumn{7}{|c|}{ Formulation } \\
\hline & $\mathrm{F} 1$ & F2 & F3 & F4 & F5 & F6 & F7 \\
\hline $\begin{array}{l}\text { Tensile strength, } \\
\text { Mpa }\end{array}$ & $8.70 \pm 0.10$ & $11.80 \pm 0.11$ & $9.71 \pm 0.04$ & $9.59 \pm 0.09$ & $9.71 \pm 0.06$ & $11.80 \pm 0.11$ & $9.16 \pm 0.05$ \\
\hline$\%$ Friability & $0.13 \pm 0.21$ & $0.24 \pm 0.25$ & $0.21 \pm 0.13$ & $0.18 \pm 0.14$ & $0.18 \pm 0.11$ & $0.21 \pm 0.05$ & $0.24 \pm 0.21$ \\
\hline $\begin{array}{l}\text { Content } \\
\text { uniformity, \% }\end{array}$ & $99.45 \pm 0.30$ & $102.11 \pm 0.39$ & $100.17 \pm 0.28$ & $100.17 \pm 0.29$ & $99.91 \pm 0.41$ & $100.88 \pm 0.45$ & $102.37 \pm 0.22$ \\
\hline Wetting time, $\mathrm{s}$ & $9.67 \pm 0.11$ & $18.0 \pm 0.32$ & $19.33 \pm 0.29$ & $14.67 \pm 0.21$ & $15.67 \pm 0.18$ & $15.33 \pm 0.19$ & $16.67 \pm 0.22$ \\
\hline $\begin{array}{l}\text { Water absorption } \\
\text { ratio }\end{array}$ & $84.62 \pm 0.19$ & $82.31 \pm 0.16$ & $84.2 \pm 0.21$ & $82.87 \pm 0.22$ & $83.27 \pm 0.11$ & $82.5 \pm 0.19$ & $83.78 \pm 0.16$ \\
\hline
\end{tabular}

*Results are the mean of 5 observations \pm SD.

polymer, indicating presence of drug in the crystalline state. However, the diffraction pattern of DPC represents complete disappearance of crystalline peaks of drug, especially those situated between $26^{\circ}$ and $60^{\circ}(2 \theta)$; whereas, the intensity of characteristic peaks of pure drug situated at $20.3^{\circ}$ and $16.6^{\circ}$ (20) was reduced and peaks were also found to be broadened. These findings suggest the formation of a new solid phase with a lower degree of crystallinity due to complexation, which coincides with the conclusion of Fernandes and Veiga. $^{23}$

The FTIR spectrum of the physical mixture of drug and polymer showed no significant shift or reduction in intensity of peaks of ondansetron $\mathrm{HCl}$. However, the FTIR spectrum of DPC was found to exhibit some significant difference in the characteristic peaks of ondansetron $\mathrm{HCl}$, revealing modification of the drug environment. As shown in Figure 2, a broad band of bonded - $\mathrm{OH}$ of ondansetron $\mathrm{HCl}$ was observed from 3481 to $3245.97 \mathrm{~cm}^{-1}$. DPC showed diminution and shifting of this peak from 3481 to $3311 \mathrm{~cm}^{-1}$. Diminution and shifting of DPC peaks suggests the formation of

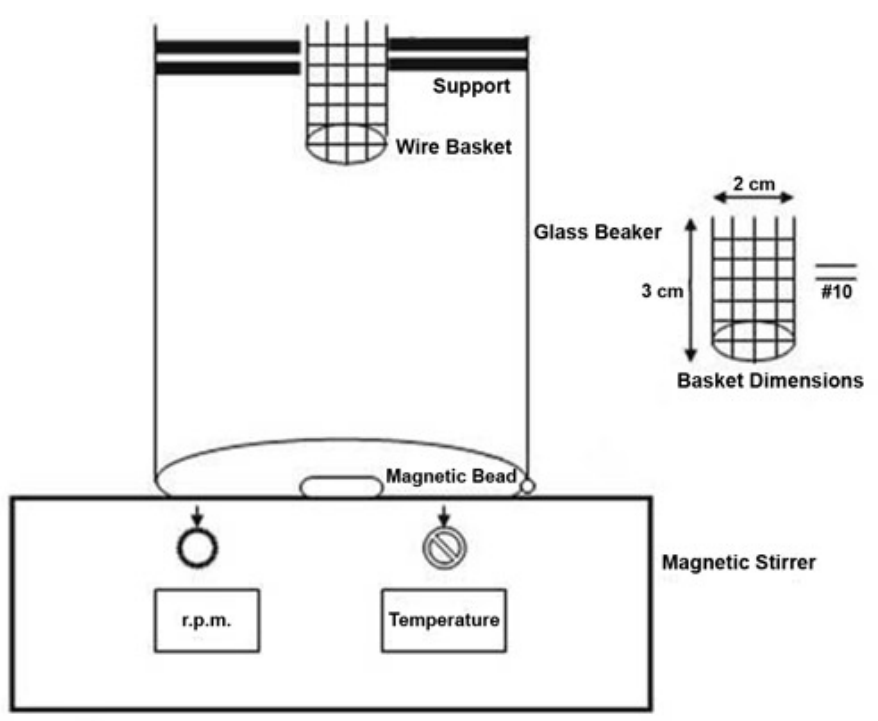

Figure 3. Schematic presentation of modified disintegration test apparatus. new N-H stretching, which was previously absent in the pure drug. This shows the probability of formation of cation on the indole ring of ondansetron $\mathrm{HCl}$ that would have formed a complex with polymer by electrostatic force of attraction due to the negative charge of the carboxylate ions.

\section{Selection of the Superdisintegrant}

Initially tablets containing superdisintegrants in the concentrations 8,10 , and $12 \% \mathrm{wt} / \mathrm{wt}$ were tested for disintegration time. Tablets containing Polyplasdone XL-10 showed quick disintegration followed by Ac-Di-Sol and Primojel. The probable reason for delayed disintegration of the tablets with Ac-Di-Sol and Primojel might be due to their tendency to gel more than Polyplasdone XL-10. This result coincides with the findings of Patel et al., ${ }^{14}$ wherein they formulated orodispersible tablets of rofecoxib. Hence, Polyplasdone XL-10 was selected for the formulation of RDTs. After selection, the concentration of Polyplasdone XL-10 was further reduced to get the minimum optimal concentration. Polyplasdone XL-10 7\% wt/wt was selected as the optimum concentration that showed minimal disintegration time of 7.33 seconds. It was observed that further increase in concentration led to the increase in disintegration time. Such delay in disintegration may be because of the higher water requirement by a larger amount of Polyplasdone XL-10, which consequently transformed into swelling force for rapid disintegration of the tablet.

\section{Physical Properties of the Tablet Blend}

The tablet blend of all the batches showed good flowability (angle of repose $<30^{\circ}$ ) and compressibility, except batch F1 with an angle of repose of $42.6^{\circ}$. Poor flowability of F1 may be attributed to the presence of only microcrystalline cellulose having filamentous particles as a diluent.

However, flowability of the blend increased with increasing concentrations of spray-dried mannitol or spray-dried lactose, as they have a spherical granular shape. 
AAPS PharmSciTech 2007; 8 (2) Article 46 (http://www.aapspharmscitech.org).

Table 6. Comparison of Disintegration Time of Rapid-Disintegrating Tablets and Marketed Tablet by Different Methods*

\begin{tabular}{|c|c|c|c|c|}
\hline \multirow[b]{2}{*}{ Formulations } & \multicolumn{4}{|c|}{ Disintegration Time, $\mathrm{s}$} \\
\hline & $\begin{array}{c}\text { USP } \\
\text { Apparatus }\end{array}$ & $\begin{array}{l}\text { Modified Apparatus } \\
\text { (50 rpm) }\end{array}$ & $\begin{array}{l}\text { Modified Apparatus } \\
\quad(25 \mathrm{rpm})\end{array}$ & $\begin{array}{c}\text { In vivo } \\
\text { Disintegration }\end{array}$ \\
\hline F1 & 6 & 10 & 11 & 12 \\
\hline $\mathrm{F} 2$ & 11 & 12 & 18 & 18 \\
\hline F3 & 12 & 17 & 19 & 19 \\
\hline F4 & 7 & 9 & 13 & 13 \\
\hline F5 & 9 & 11 & 13 & 13 \\
\hline F6 & 10 & 10 & 14 & 14 \\
\hline F7 & 9 & 12 & 15 & 15 \\
\hline Marketed mouth dissolving tablet & 68 & 100 & 105 & 112 \\
\hline
\end{tabular}

*Results are the mean of 3 observations.

\section{Wetting, Disintegration Time, Taste, and Sensory Evaluation of RDTs}

Properties like hardness, friability, weight variation, and content uniformity of tablets of all the batches were found to be within acceptable limits.

Tablets of batch F4 containing spray-dried mannitol and microcrystalline cellulose in the ratio $1: 1$ and $7 \% \mathrm{wt} / \mathrm{wt}$ Polyplasdone XL-10 showed faster disintegration, within 12.5 seconds, than the marketed tablet (112 seconds). The difference was significant with a $P$ value less than .01 . Batch F6, containing a higher amount of spray-dried mannitol, showed increased wetting and disintegration time. Increase in wetting and disintegration time may be due to the increase in polyol quantity in the tablet formulation. As polyols are readily soluble in water, there exists a competition between spray-dried mannitol and Polyplasdone XL-10 for water penetrating into the tablet, consequently leading to poor swelling of Polyplasdone XL-10 with subsequent delay in disintegration. ${ }^{24}$ Disintegration time of tablets of batch F5 containing microcrystalline cellulose and spray-dried lactose in a 1:1 ratio was also slightly more than F4, probably because of the formation of a sticky layer due to the dissolution of lactose and subsequent hindrance in the further ingress of water into the tablet.

Table 7. Comparative Taste Evaluation*

\begin{tabular}{lllllll}
\hline & \multicolumn{6}{c}{ Degree of Bitterness After Time } \\
\cline { 2 - 7 } $\begin{array}{llllll}\text { Form of } \\
\text { Ondansetron HCl }\end{array}$ & $10 \mathrm{~s}$ & $\begin{array}{c}1 \\
\min \end{array}$ & $\begin{array}{c}2 \\
\min \end{array}$ & $\begin{array}{c}5 \\
\min \end{array}$ & $\begin{array}{c}10 \\
\min \end{array}$ & $\begin{array}{c}15 \\
\min \end{array}$ \\
\hline $\begin{array}{l}\text { Pure drug } \\
\text { DPC }\end{array}$ & 0.5 & 3 & 3 & 3 & 2 & 2 \\
$\begin{array}{l}\text { Unflavored } \\
\text { tablet of DPC }\end{array}$ & 0 & 0 & 0.5 & 0.5 & 0 & 0 \\
$\begin{array}{l}\text { Flavored } \\
\text { tablet of DPC }\end{array}$ & $0+$ & $0+$ & $0+$ & $0+$ & $0+$ & $0+$ \\
\hline
\end{tabular}

*Results are the mean of 11 observations.

+ indicates palatability; DPC, drug-polymer complex.
Between the 2 stirrer speeds, $25 \mathrm{rpm}$ was found to provide more comparable results with the in vivo test. Disintegration times of tablets from all the batches at $25 \mathrm{rpm}$ were found nearly same as in vivo disintegration time (Table 6). Thus, the test apparatus with a stirring speed of $25 \mathrm{rpm}$ was considered the most suitable.

The time intensity study for taste in human volunteers of both the DPC and RDT revealed considerable masking of the bitter taste of ondansetron $\mathrm{HCl}$ with degree of bitterness below the threshold value $(0.5)$ ultimately reaching to 0 within 15 minutes. Sensory evaluation of the optimized tablet proved good palatability.

\section{Drug Release from RDT}

From the results of the tests, tablets of batch F4 were considered to posses the best physical properties accompanied with quick disintegration and, therefore, tested and compared with the marketed tablet for dissolution. The dissolution study of the optimized tablet revealed rapid release

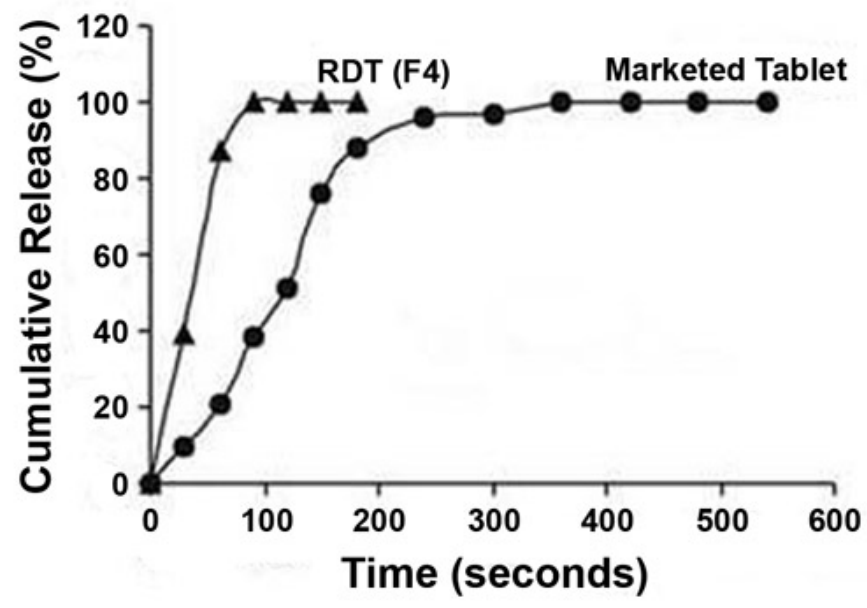

Figure 4. Dissolution profiles of optimized rapid-disintegrating tablet (RDT) (F4) and marketed tablet. 


\section{AAPS PharmSciTech 2007; 8 (2) Article 46 (http://www.aapspharmscitech.org).}

of drug ( $t_{90}$ of approximately 60 seconds) in SGF compared with marketed formulation, which had a $t_{90}$ of approximately 240 seconds. Thus, a significant $(P<.01)$ difference in the dissolution patterns of the prepared and marketed formulations was observed. The dissolution process might have involved both ion exchange and solubilization of Eudragit EPO.

\section{CONCLUSION}

The study conclusively demonstrated complete taste masking of ondansetron $\mathrm{HCl}$ and rapid disintegration and dissolution of RDT. Taste masking and rapid disintegration of tablets formulated in this investigation may possibly help in administration of ondansetron $\mathrm{HCl}$ in a more palatable form without water during emesis.

Thus, the "patient-friendly dosage form" of bitter drugs, especially for pediatric, geriatric, bedridden, and noncooperative patients, can be successfully formulated using this technology.

\section{REFERENCES}

1. Hanawa T, Watanabe A, Tsuchiya T, Ikoma R, Hidaka M, Sugihara $\mathrm{M}$. New oral dosage form for elderly patients: preparation and characterization of silk fibroin gel. Chem Pharm Bull (Tokyo). 1995;43:284-288.

2. Ishikawa T, Watanabe Y, Utoguchi N, Matsumoto M. Preparation and evaluation of tablets rapidly disintegrating in saliva containing bitter taste masked granules by compression method. Chem Pharm Bull (Tokyo). 1999;47:1451-1454.

3. Koizumi K, Watanabe Y, Morita K, Utoguchi N, Matsumoto M. New method for preparing high porosity rapidly saliva soluble compressed tablets using mannitol with camphor, a subliming material. Int J Pharm. 1997; 152:127-131.

4. Kaushik D, Dureja H, Saini TR. Mouth dissolving tablets: A review. Indian Drugs-Bombay. 2004;41:187-193.

5. Chue $\mathrm{P}$, Welch R, Binder C. Acceptability and disintegration rates of orally disintegrating risperidone tablets in patients with schizophrenia or schizoaffective disorders. Can J Psychiatry. 2004;49:701-703.

6. Shu T, Suzuki H, Hironaka K, Ito K. Studies of rapidly disintegrating tablets in oral cavity using coground mixture of mannitol with crospovidone. Chem Pharm Bull (Tokyo). 2002;50:193-198.

7. Seager H. Drug delivery products and the zydis fast dissolving dosage form. J Pharm Pharmacol. 1998;50:375-378.

8. Gohel M, Patel M, Amin A, Agrawal R, Dave R, Bariya N. Formulation design and optimization of mouth dissolve tablets of nimesulide using vacuum drying technique. AAPS PharmSciTech. 2004;5:E36.
9. Chang RK, Guo X, Burnside BA, Couch RA. Fast dissolving tablets. Pharm Technol. 2000;24:52-58.

10. Shimizu T, Sugaya M, Nakano Y, et al. Formulation study for lansoprazol fast disintegrating tablet, III. Design of rapidly disintegrating tablets. Chem Pharm Bull (Tokyo). 2003;51:1121-1127.

11. Thomson Micromedex Healthcare. Ondansetron hydrochloride (systemic). In: Drug Information for Health Care Professionals: USP DI. Greenwood Village, CO: Micromedex Thomson Healthcare; 2001:2248-2250.

12. Johnson BA, Roache JD, Javors MA, et al. Ondansetron for reduction of drinking among biologically predisposed alcoholic patients. JAMA. 2000;284:963-971.

13. Reddy LH, Gosh BR. Fast dissolving drug delivery system: A Review of the literature. Indian J Pharm Sci. 2002;64:331-336.

14. Patel DM, Patel NM, Shah RR, Jogani PL, Balapatel AI. Studies in formulation of orodispersible tablets of rofecoxib. Indian J Pharm Sci. 2004;66:621-625.

15. United States Pharmacopeia 24/NF 19. The Official Compendia of Standards. Asian ed. Rockville, MD: United States Pharmacopoeial Convention Inc; 2000:1913-1914.

16. Kuchekar BS, Badhan AC, Mahajan HS. Mouth dissolving tablets of salbutamol sulphate: a novel drug delivery system. Indian Drugs. 2004;41:592-598.

17. Morita Y, Tsushima Y, Termoz R, Ajioka J, Takayama K. Evaluation of disintegration time of rapidly disintegrating tablets via a novel method utilizing a CCD camera. Chem Pharm Bull (Tokyo). 2002;50:1181-1186.

18. Watanabe Y, Yamamoti Y, Fujii M, Kondoh M, Shibata Y. A novel method for predicting disintegration time in the mouth of rapid disintegrating tablet by compaction analysis using Tab AII. Chem Pharm Bull (Tokyo). 2004;52:1394-1395.

19. Narazaki R, Harada T, Takami N, Koto Y, Ohwaki T. A new method for disintegration studies of rapid disintegrating tablets. Chem Pharm Bull (Tokyo). 2004;52:704-707.

20. Watanabe Y, Ishikawa T, Mukai B, et al. Preparation of RDT using new type of microcrystalline cellulose (PH M series) and low substituted hydroxy propyl cellulose or spherical sugar granules by direct compression method. Chem Pharm Bull (Tokyo). 2001;49: 134-139.

21. Uchida T, Nakamura T, Tanigake A, et al. The effect of various substances on the suppression of the bitterness of quinine-human gustatory sensation, binding, and taste sensor studies. Chem Pharm Bull (Tokyo). 2002;50:1589-1593.

22. Borodkin N, Sundberg DP. Polycarboxylic acid ion exchange resin adsorbates for taste coverage in chewable tablets. J Pharm Sci. 1971;60:1523-1527.

23. Fernandes CM, Veiga FJ. Effect of hydrophobic nature of triacetyl$\beta$-cyclodextrin on the complexation with nicardipine hydrochloride: physicochemical and dissolution properties of the kneaded and spraydried complexes. Chem Pharm Bull (Tokyo). 2002;50:1597-1602.

24. Schiermeier S, Schmidt PC. Fast dispersible ibuprofen tablets. Eur J Pharm Sci. 2002;15:295-305. 